\title{
Observations at the CNS-PNS border of ventral roots connected to a neuroma
}

\author{
Sten Remahl' , Maria Angeria', Ingela Nilsson Remahl ${ }^{2}$, Thomas Carlstedt ${ }^{3}$ and Mårten Risling ${ }^{1 *}$ \\ Department of Neuroscience, Karolinska Institutet, Stockholm, Sweden \\ 2 Department of Clinical Neuroscience, Division of Neurology, Karolinska Institutet, Karolinska University Hospital Huddinge, Stockholm, Sweden \\ ${ }^{3}$ Department of Clinical Science and Education, Hand Surgery, Södersjukhuset, Stockholm, Sweden
}

\section{Edited by:}

Peter Shortland, Barts and The London School of Medicine and Dentistry, UK

\section{Reviewed by:}

Peter Shortland, Barts and The London School of Medicine and Dentistry, UK Leif A. Havton, University of California at Los Angeles Neurorehabilitation and Research Center, USA

\section{*Correspondence:}

Mårten Risling, Department of Neuroscience, Experimental

Traumatology Unit, Retzius väg 8 , Karolinska Institutet, S-171 77

Stockholm, Sweden.

e-mail: marten.risling@ki.se
Previous studies have shown that numerous sprouts originating from a neuroma, after nerve injury in neonatal animals, can invade spinal nerve roots. However, no study with a focus on how such sprouts behave when they reach the border between the central and peripheral nervous system (CNS-PNS border) has been published. In this study we have in detail examined the CNS-PNS border of ventral roots in kittens with light and electron microscopy after early postnatal sciatic nerve resection. A transient ingrowth of substance $P$ positive axons was observed into the CNS, but no spouts remained 6 weeks after the injury. Using serial sections and electron microscopy it was possible to identify small bundles of unmyelinated axons that penetrated from the root fascicles for a short distance into the CNS. These axons ended blindly, sometimes with a growth cone-like terminal swelling filled with vesicles. The axon bundles were accompanied by 75 positive cells in both the root fascicles and the pia mater, but not in the CNS. It may thus be suggested that neurotrophin presenting $p 75$ positive cells could facilitate axonal growth into the pia mater and that the lack of such cells in the CNS compartment might contribute to the failure of growth into the CNS. A maldevelopment of myelin sheaths at the CNS-PNS border of motor axons was observed and it seems possible that this could have consequences for the propagation of action potential across this region after neonatal nerve injury. Thus, in this first detailed study on the behavior of recurrent sprouts at the CNS-PNS border.

Keywords: cat, nerve lesion, sprouting, electron microscopy, immunohistochemistry, regeneration, PNS-CNS transition

\section{INTRODUCTION}

In pioneering studies it was shown by Coggeshall and co-workers that ventral roots of cats and man contain a large proportion of unmyelinated sensory axons (Coggeshall et al., 1974; Coggeshall, 1980), the ventral root afferents (VRA). At some levels the VRA comprise about $30 \%$ of the population; thus, some 1500-2000 unmyelinated sensory axons are present in the ventral root L7 of adult cats (Coggeshall et al., 1974; Risling et al., 1981; Nilsson Remahl et al., 2008). Rats seem to have a much smaller population of VRA (Coggeshall et al., 1977), and may therefore be less suitable for studies on the biology and significance of VRA. The proportion of VRA can increase in relation to neonatal nerve injury and possibly also as a systemic response to certain neoplasms (Risling and Hildebrand, 1981). The VRA have been implicated to carry sensory information from the pia mater and also to be the background for the pain sensitivity of the ventral roots that was described by Magendie and in clinical studies (Frykholm et al., 1953; White and Sweet, 1955; Cranefield, 1974). Thus, VRA could possibly be described as a type of nervi nervorum, an innervation of the nerve tissue, blood vessels or the surrounding connective tissue, and could exert a role for pain transmission in response to disc herniation or other spinal injuries. A number of studies indicate that VRA finally enter through the dorsal root, in good agreement with the law of Magendie (Cranefield, 1974; Risling et al., 1987). Most of them seem to have their cell bodies in the dorsal root ganglion, although some may be attributed to aberrant sensory neurons in ventral roots (Risling et al., 1994).
It has been observed that the number of VRA in lumbosacral ventral roots of cats is more than doubled during late postnatal development (Risling et al., 1981; Risling and Hildebrand, 1982), or adolescence. It has recently been suggested that this expansion of the VRA could be facilitated by the presence of vacant Schwann cells that have been unemployed as a result of an elongation of the internodal length of the motor axons in the lumbosacral ventral roots (Nilsson Remahl et al., 2008). An even more drastic ingrowth of unmyelinated axons can take place in response to early postnatal sciatic nerve injury (Ramón y Cajal, 1928; Risling et al., 1984a,c). A large number of these axons seem to contain substance P (Risling et al., 1984a) and may therefore be assumed to have a sensory origin. Ventral roots connected to a sciatic neuroma can contain more than 10,000 unmyelinated axons and the majority of these seem to disappear after removal of the neuroma (Risling et al., 1984c). It is unknown if the lesion induced VRA could generate or transmit pain. It appears possible that this ingrowth of lesion induced VRA is facilitated by a retrograde cell death that occurs. In contrast to the situation in adults (Risling et al., 1983a), about $30 \%$ of the motor axons disappear after early postnatal sciatic neurectomy (Risling et al., 1980) and therefore results in a large number of vacant Schwann cells.

In this study we studied the border between the central (CNS) and peripheral nervous systems (PNS) to examine the appearance of the invading sprouts when they reach the CNS-PNS border. We demonstrate a limited and transient ingrowth of sprouts into 
the spinal cord. We also show that this early postnatal lesion has adverse effects on the development of myelin sheaths on motor axons at the CNS-PNS border.

\section{MATERIALS AND METHODS SURGERY}

Tissue from 22 kittens were used. The studies followed standard ethical guidelines and were approved by the institutional oversight ethics committee on animal research. At the age of 7 days the animals were anesthetized with Halothane ${ }^{\circledast}$ and the left sciatic nerve was divided about $10 \mathrm{~mm}$ below the origin of the hamstring nerve branch. The distal stump of the lesioned sciatic nerve was resected down to the popliteal fossa and the wound was closed. After a postoperative survival time of 21-200 days, the animals were anesthetized with pentobarbitone sodium ( $40 \mathrm{mg} / \mathrm{kg}$ i.p. $)$ and perfused through the descending aorta with Tyrode's solution followed by ice-cold $10 \%$ formalin $(n=4)$ or $5 \%$ glutaraldehyde in phosphate buffer $(n=4)$. The lumbosacral spinal cord was exposed and removed in one piece with its ventral spinal ventral roots. Quantitative findings from the ventral roots have been reported in previous studies (Risling et al., 1984c). For the purpose of obtaining a detailed analysis of the CNS-PNS border, the ventral funiculus with adhering L7 and S1 ventral root fascicles was identified and dissected in one block. From specimens that had been fixed with formalin the S1 segment was prepared for transverse sectioning with a cryostat. The pia mater covering the L7 segment with adhering ventral L7 root fascicles was stripped off and used as a stretch specimen for immunogold labeling (see below).

\section{PREPARATION AND ANALYSIS}

\section{Immunofluorescence}

Paraformaldehyde fixed tissue from seven animals surviving for 3 weeks $(n=3), 6$ weeks $(n=2)$ and 12 weeks $(n=2)$, plus four agematched controls, were used for this part of the study. Fourteen micrometer thick transverse sections were cut from the L7 segments, with the juxtamedullary ventral root fascicles remaining in continuity and incubated overnight a monoclonal substance $\mathrm{P}$ antiserum (raised in rats; Sera-lab, UK; dilution 1:200), a mousemonoclonal antibody against the human p75 neurotrophin receptor (Risling et al., 1992a; dilution 1:100, this antibody (IgG1-kappa) was produced from a mouse hybridoma 200-3G6-4) or a mousemonoclonal antibody raised against a growth-associated protein (Risling et al., 1994) GAP-43 (1:2000, kindly provided by Drs. D.J. Schreyer and J.H.P. Skene). The sections were analyzed in a Nikon epi-fluorescence microscope.

\section{Electron microscopy}

Four kittens were perfused after a postoperative survival of 90-180 days with a fixative composed $5 \%$ glutaraldehyde and $0.1 \mathrm{M}$ sucrose in a $300 \mathrm{mOsm}$ phosphate buffer (Carlstedt, 1977). After fixation the lumbosacral spinal cord was removed in one piece together with its spinal roots. Following postfixation in the fixative, specimens composed of ventral funiculus strips from the segment L7 with the ventral roots remaining attached were trimmed out. After buffer rinse, osmication, and acetone-dehydration the specimens were embedded in Vestopal $W^{\circledast}$. After light microscopic examination of semithin toluidine-blue stained ( $1 \%$ solution) sections an area containing some juxtamedullary ventral root fascicles, the superficial part of the ventral funiculus and the pia mater were trimmed out. From each of the Vestopal-embedded specimens, short series containing 50-100 ultrathin sections were cut with glass knives on an LKB Ultrotome ${ }^{\circledast}$ III. After contrasting with a saturated solution of uranyl acetate and a $0.08 \mathrm{M}$ lead citrate solution, the sections were examined in an electron microscope. From one of the animals, a series of about 1100 consecutive ultrathin transverse sections was cut. Sections from three normal 3- to 4-month old kittens were used as controls. The sections were examined in electron microscope. Unmyelinated axons were examined at a magnification of 25,000×. Myelin lamellae from selected axons were counted directly in the electron microscope at a magnification of $80,000 \times$.

\section{Immunogold labeling}

A separate set of specimens intended for immunogold-silver staining (IGS) were obtained from three cats, fixed with paraformaldehyde $(4 \%)$ and $0.1 \%$ glutaraldehyde. Pia mater/ventral root preparations from three additional animals (180-days survival) were dehydrated in a graded series of ethanol, rehydrated, and incubated with the substance $P$ antiserum, the mouse-monoclonal antibody against the human p75 neurotrophin receptor or the mouse-monoclonal antibody raised against the axonal growth-associated protein GAP-43 antibody (the same antibodies that were used for immunofluorescence, and in the same concentration) with appropriate secondary antibodies at $22^{\circ} \mathrm{C}$ for $30 \mathrm{~min}$. After rinsing, the specimens were incubated with a 1-nm gold particle conjugated secondary antibodies (AuroProbe One, Amersham, UK; dilution 1:50) for $1 \mathrm{~h}$. These preparations were rinsed and the gold staining was visualized for light microscopy using a silver enhancement reaction (Intense M, Jansen Biotech, Belgium). The specimens were osmicated according to a modification of the Marchi method (Hildebrand and Aldskogius, 1976). All preparations were carefully rinsed in PBS with IGS gelatin and EM-grade distilled water and the gold staining was visualized for light microscopy using a silver enhancement reaction (Intense M, Amersham, UK). After rinsing, these specimens were dehydrated with acetone and infiltrated with Vestopal $\mathrm{W}^{\circledast}$. Finally the pia mater with adhering juxtamedullary ventral root fascicles were stretched out on an acetate-folio and the preparation was allowed to polymerize. The whole mount preparation could then be examined in a light microscope and thin silver-gray sections from selected areas were collected on 460 hex mesh grids (Polaron, UK) using glass knives and an LKB Ultrotome. The sections were contrasted with uranyl acetate and lead citrate and examined in a Philips CM12 electron microscope operated at $80 \mathrm{kV}$.

In one additional case (90-days survival) intended for immuno electron microscopy was perfused with a mixture of paraformaldehyde (4\%) and glutaraldehyde (1\%) in phosphate buffer. These specimens were not osmicated and were dehydrated in a graded series of ethanol and embedded in LR White ${ }^{\varpi}$ (Polaron, UK). Thin silver-gray sections from the CNS/PNS border on both the experimental and control sides were collected on uncoated 460hex meshgrids (Polaron, UK). These grids were incubated on $50 \mu$ l droplets of substance $\mathrm{P}$ antibodies (dilution 1:200) for $2 \mathrm{~h}$ at $22^{\circ} \mathrm{C}$. After rinsing in $\mathrm{PBS}$, the grids were incubated at $22^{\circ} \mathrm{C}$ for $1 \mathrm{~h}$ in a goldcoupled goat-antirabbit IgG (Polak and Noorden, 1986) (10 nm size; dilution 1:10; BioCell Research labs, Cardiff, UK). In order to 
evaluate if non-specific binding of the gold-labeled second layer antibody occurred, incubation with the primary antibody was excluded in some cases. Following incubation with antisera, the sections were rinsed in PBS and distilled water. Finally, the grids were contrasted with uranyl acetate and lead citrate and examined in the electron microscope.

\section{RESULTS}

\section{LIGHT MICROSCOPY}

Compared to normal young cats, the content of substance P (SP) positive nerve fibers was markedly elevated in the juxtamedullary L7/S1 ventral roots ipsilateral to the neuroma in all operated kittens surviving longer than 14 days after the sciatic nerve lesion. In agreement with previous observations, these axons were also positive for the p75 receptor and GAP-43 (Risling et al., 1994). The p75 antibody also stained meningeal cells in the pia mater (Risling et al., 1992a; Frisén et al., 1998). Three weeks after the operation a number of SP-immunoreactive axons were observed also in the superficial part of the ventral funiculus (Figure 1A). No penetrating axons could be detected in the controls. No penetrating SP-immunoreactive axons could be detected in animals surviving longer than 4 weeks. From four weeks on penetrating SP positive axons, reaching beyond the superficial layers of the ventral root CNS compartment, appeared to be absent. The immunogold labeling with silver enhancement provided a strong staining of a SP- and GAP43-immunoreactive axons within the root fascicles. Individual axons or bundles of axons could be followed for several hundreds of microns in the fascicles and into the pia mater (Figure 1B). Examples of blindly ending immunoreactive axons were found in the juxtamedullary ventral root fascicles (Figure 1C).

\section{ELECTRON MICROSCOPY}

Examination of thin sections from ventral roots connected to sciatic neuromas, in kittens surviving for 90 days after the operation, showed that numerous bundles composed of unmyelinated axons and thin myelinated axons occurred on both sides of the CNS-PNS border and in the pia mater ventral to the spinal cord (Figures 1D-F). The bundles in the pia mater lacked a defined root sheath and other connective tissue components, that would be present in ventral root fascicles. In control ventral roots occasional unmyelinated axons could be detected in the PNS compartments of juxtamedullary ventral root fascicles but not in the CNS compartment. Using serial sections from ventral roots ipsilateral to the sciatic nerve resection, tiny bundles of unmyelinated axons and small myelinated axons could be followed across the CNS-PNS border in each examined fascicle. However, when unmyelinated axons were traced within the CNS compartment of the root fascicles it was observed that all such unmyelinated axons disappeared as the spinal cord was approached, or within a few microns inside the ventral funiculus (Figure 2). Some axons were shown to end blindly with a large terminal swelling (Figure 3 ).

A number of large unmyelinated axon profiles filled with numerous mitochondria and vesicles were observed at the CNSPNS border (Figure 4A) and adjacent to blood vessels in the pia mater (Figures $4 \mathrm{~B}-\mathrm{D}$ ). Some of these axon profiles with a close vascular relation (Figures $4 \mathrm{~B}, \mathrm{C}$ ) were only partly invested by a
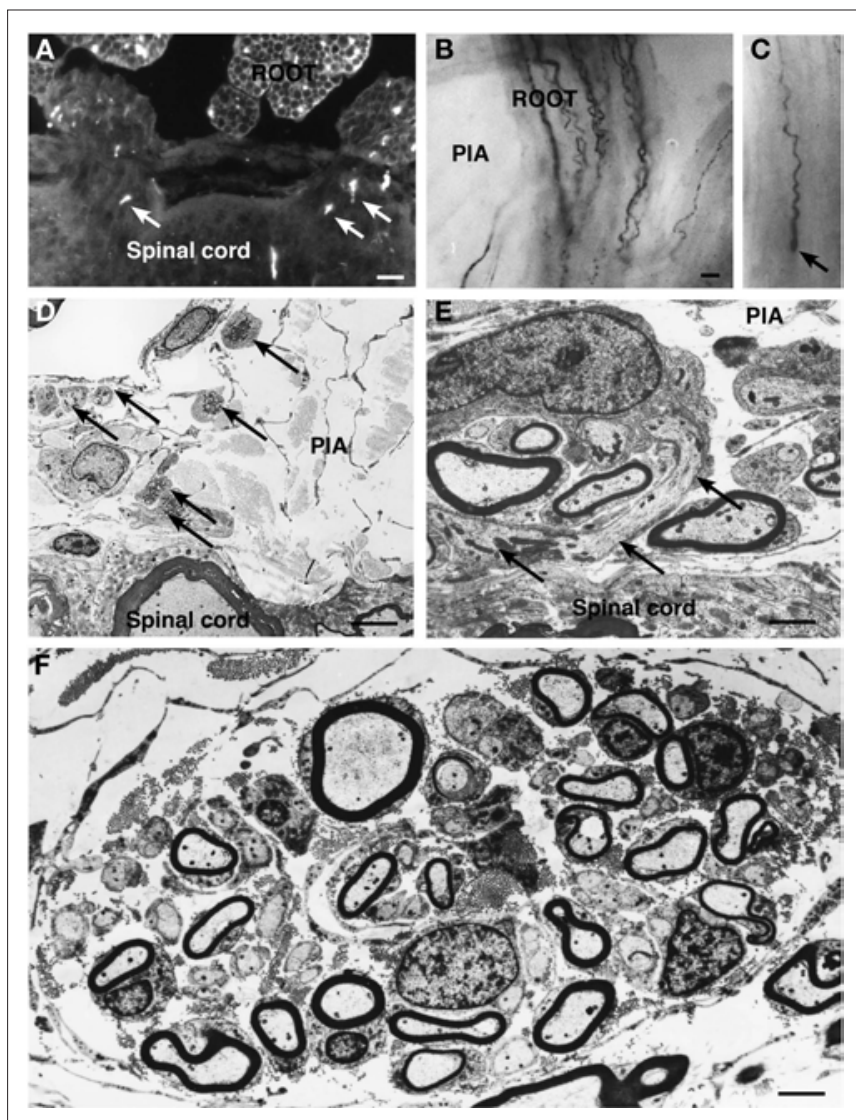

FIGURE 1 | In a cryostat sections from the spinal cord from a kitten surviving for 3 weeks after sciatic nerve resection SP-immunoreactive fibers, indicated by arrows, are seen in the ventral funiculus (A). The light micrographs in (B) and (C) show GAP-43 immunoreactive fibers, visualized by immunogold and silver enhancement, in a whole mount preparation of the pia mater (PIA) with ventral root (ROOT) fascicles. Numerous immunoreactive axons can be followed from the fascicle to the pia mater. (C) A blindly ending GAP-43 positive fiber (arrow) is observed in the proximal end of the ventral root fascicle. (D) An electron micrograph showing small bundles (arrows) of unmyelinated and thin myelinated axons in the pia mater (PIA) adjacent to the spinal cord. The large unmyelinated axon in (D) seems to end with an

accumulation of mitochondria just outside the spinal cord. (E,F) Examples of larger bundles of unmyelinated and small myelinated axons in the pia mater, adjacent to the ventral root fascicles. Scale bar $=5 \mu \mathrm{m}(\mathbf{A})$, and $1 \mu \mathrm{m}$ (B-F).

basal lamina. Examination at a higher magnification revealed that both electron lucent and dense cored vesicles were present in this type of axon profiles (Figure 4D). Electron-microscopic examination of LR-White sections incubated with substance SP-antiserum revealed a number axon-like profiles labeled with gold particles (Figure 5A). Labeling was observed only in axon profiles that contained vesicle-like structures, to which the gold-labeled antibody complex preferentially appeared to attach. These gold-labeled axons represented only a fraction of the unmyelinated axons that were present at the CNS-PNS border. A number of unlabeled axons containing vesicles were likewise observed in the vicinity to the CNS-PNS border.

Electron-microscopic examination of specimens incubated with p75 antibodies, gold-conjugated secondary antibodies visualized by silver enhancement revealed a labeling of 

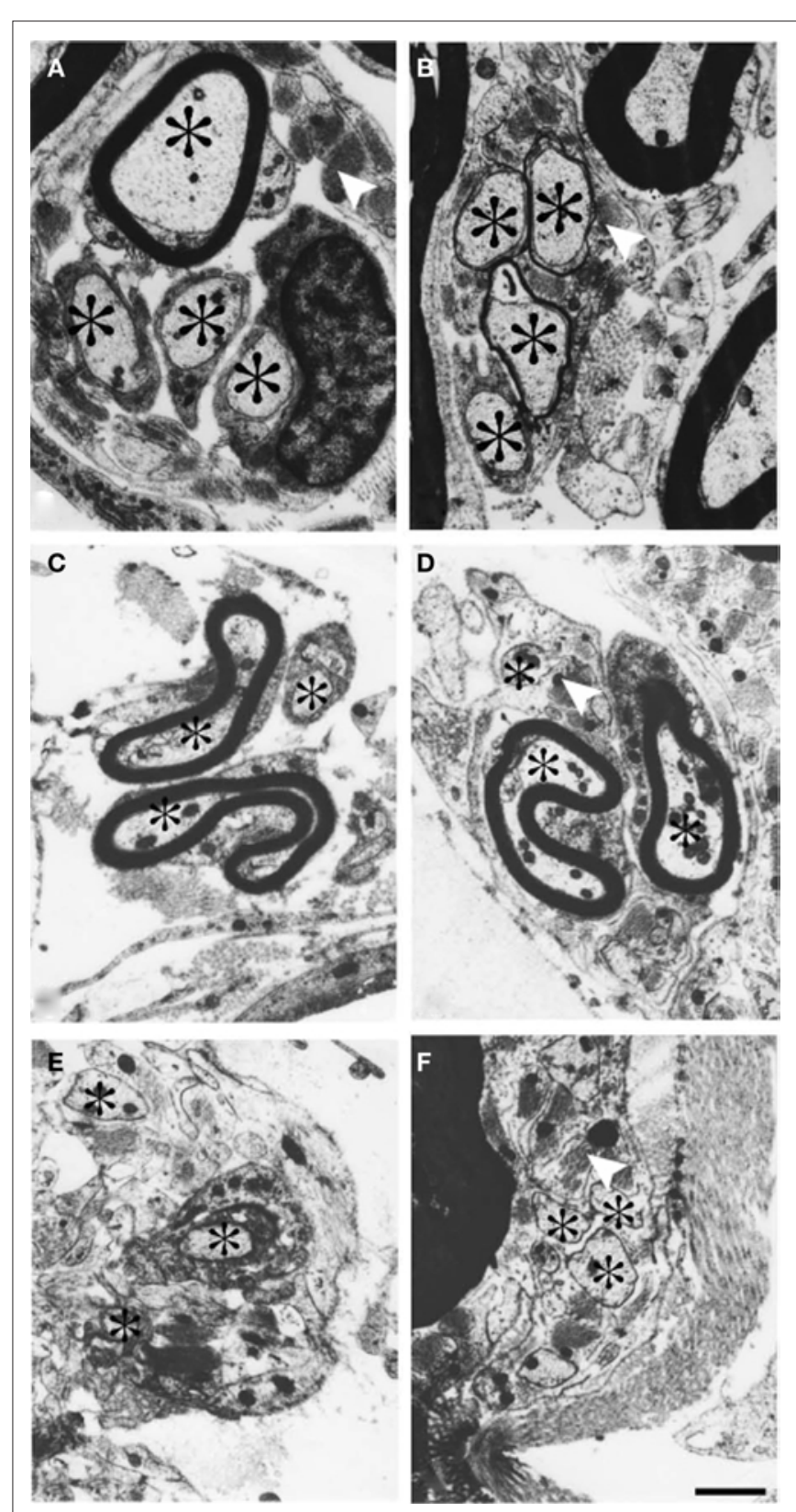

FIGURE 2 | Electron micrographs from a cat surviving for 90 days after sciatic nerve resection. (A,B) A small bundle of axons (asterisk) which was followed in a series of thin sections. At a distal level (A) the axons in the bundle are invested by Schwann cells. A few astrocytic processes are observed in the vicinity. At a more proximal level (B) all the axons in the bundle have entered the CNS compartment of the root fascicle and are surrounded by thin astrocytic processes. The electron micrographs (C-F) show another cluster of axons. At a distal level the bundle was located in the PNS compartment of the fascicle (C). At more proximal levels the bundle entered the CNS compartment of the fascicle and becomes surrounded by astrocytic processes (indicated by white arrowheads) (D-F). Scale bar $=1 \mu \mathrm{m}$.

p75-immunoreactive unmyelinated axons and non-neuronal cells in ventral root fascicles ipsilateral to the lesion (Figure 5B) and in the pia mater. A few of p75 immunoreactive cells in the fascicles did resemble reactive Schwann cells, with a basal lamina, whereas the majority of p75 positive cells in the in the juxtamedullary root

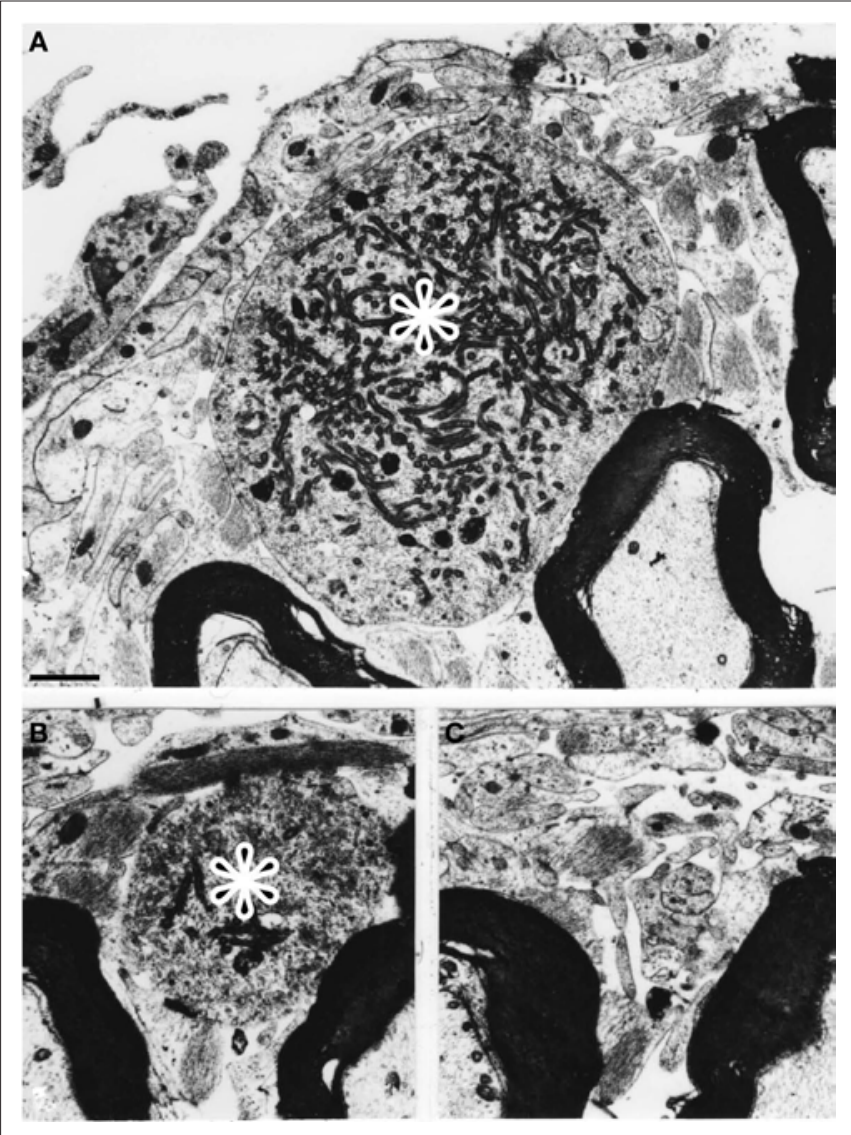

FIGURE 3 | Electron micrographs from a cat surviving for 90 days after the nerve injury. (A) The terminal enlargement of an unmyelinated axon is shown (indicated by the asterisk). Proximally the axon became gradually smaller (B) and was not longer present at the level illustrated in (C). (magnification in $\mathbf{A}-\mathbf{C}$ ) Scale bar $=1 \mu \mathrm{m}$.

fascicles pia mater appeared to be of leptomeningeal origin and lacked a basal lamina (Figure 5C). The p75 labeling of meningeal cells and the presumed reactive Schwann cells was generally membrane associated. Examination of sections incubated with GAP-43 antibodies followed by gold labeling and silver enhancement showed numerous GAP-43 immunoreactive unmyelinated axons in both ventral root fascicles and the pia mater (Figure 5D), but not within the spinal cord. This labeling was confined to the axoplasm. Control sections, incubated with only secondary antibodies and silver did not show any specific labeling.

On the central side of the CNS-PNS border it was observed that myelinated axons of different sizes sometimes had, in relation to their axon-diameter, a very short and thin myelin sheath (Figure 6). Thus, the length of the most distal CNS internode was unusually short (Figure 6A). A few axons, in the gamma size-range, were myelinated both in the CNS and PNS and presented a short unmyelinated segment at this level (Figure 6B). No, other changes in the general configuration of the CNS-PNS border zone could be detected. Thus, the shape of the glial fringe, the length of the CNS compartment that protruded into the root fascicles as well as the density of blood vessels, was similar to the organization in control specimens. 

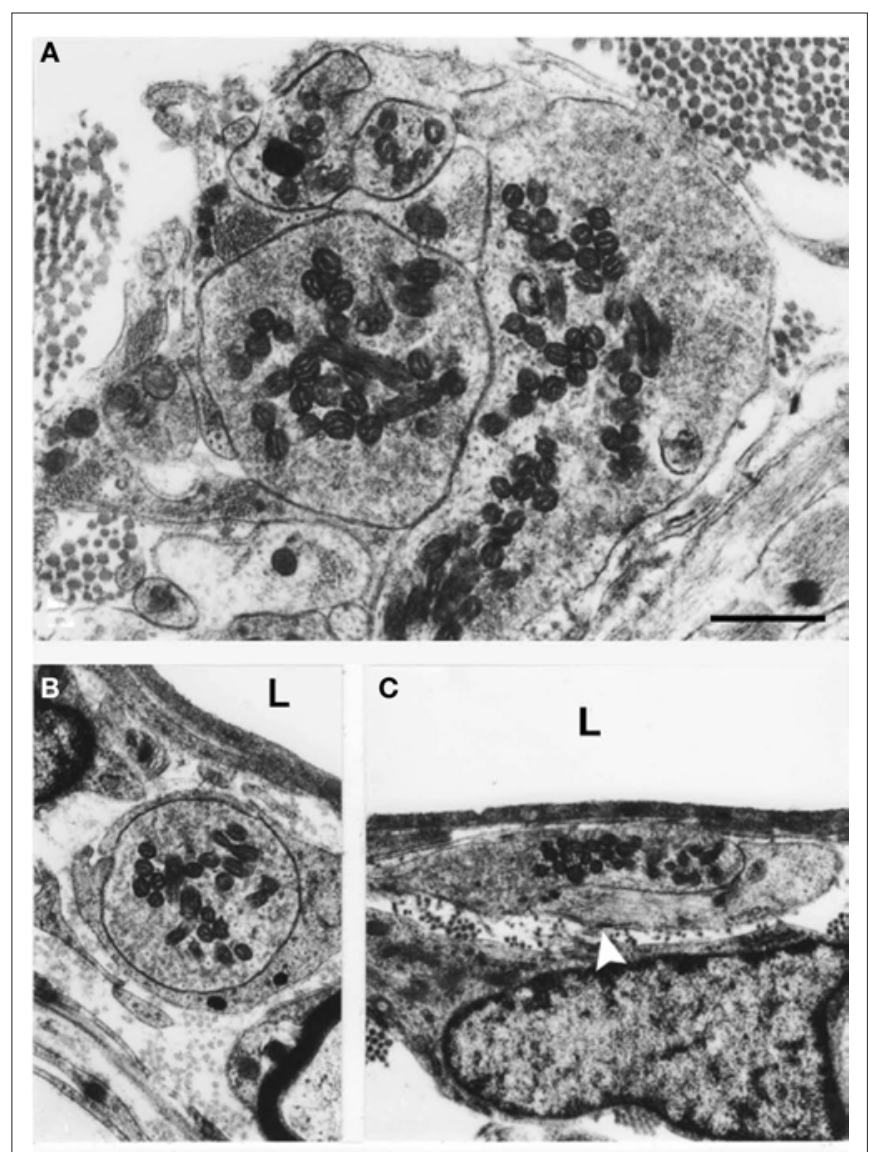

C L
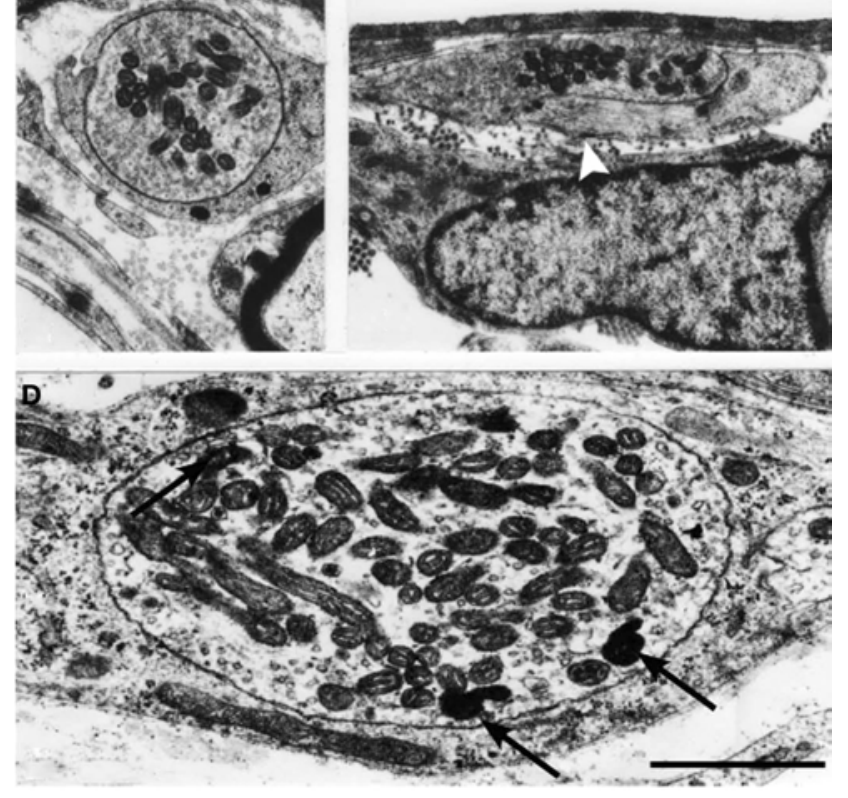

FIGURE 4 | Electron micrographs showing a thin section from the CNS-PNS border of a cat, 90 days after sciatic nerve resection. A number of large unmyelinated axons filled with mitochondria and vesicles were observed at the PNS/CNS border (A) and in the pia mater (B-D). The axons shown in $\mathbf{( B , C )}$ had a perivascular location. The axon profile in $\mathbf{( C )}$ is only invested partly by a basal lamina (white arrowhead). In most cases, the content of vesicles was heterogeneous. The lumen of the blood vessels is indicated by "L." The axon shown in (D) contained electron lucent vesicles as well as a number of dense cored vesicles (arrows) (magnification in A-C). Scale bars $=0.5 \mu \mathrm{m}$.

\section{DISCUSSION}

A massive growth of retrograde sprouts after neonatal nerve injuries was described in the work of Ramón y Cajal (1928). Our previous studies have shown that ventral roots connected to sciatic neuromas may accommodate thousands of sprouts (Risling et al., 1984c) and that many of the sprouts probably originate from sensory axons (Risling et al., 1984a). The results of the present study show that unmyelinated axons penetrate the CNS-PNS border of the L7 ventral root after sciatic neuroma formation in young kittens. At least some of these sprouts are SP-immunoreactive and reach the ventral funiculus. Within a few weeks these axons were eliminated from the ventral funiculus, although short segments could appear to persist in CNS compartment of the fascicles. Interestingly, during the normal ingrowth of sensory axons (VRA) that takes place in the lumbosacral ventral root of the cat no axons have been found to really enter the CNS (Risling et al., 1984b). In contrast, after lesions in the white matter the CNS-PNS border is reorganized and allows for a significant growth of axons from the CNS into the nerve root (Risling et al., 1983b). A similar growth can be seen across the regenerated CNS-PNS border after ventral root replantation (Carlstedt et al., 1988, 1989, 2000; Cullheim et al., 1989).

The immunohistochemical studies showed that the invading axons have a phenotype similar to previous descriptions of the normal VRA (Risling et al., 1994). Thus, they were found to be labeled with antibodies against substance $\mathrm{P}$ and GAP-43. The substance $\mathrm{P}$ labeling was found to be located to dense core vesicles. It is unlikely that the ingrowing VRA would establish any functional contacts within the spinal cord. This is in general agreement with the observations of a failure of primary sensory axons to reenter the spinal cord after dorsal root lesions (Carlstedt, 1985). However, it might be possible that the recurrent axons could exert vascular effects at the border region or in the pia mater. Furthermore, recurrent sprouts from a neuroma might induce increased pain sensitivity in the root fascicles or the pia mater. It has been described in clinical cases that both the ventral root and the ventral pia mater is pain sensitive (Frykholm et al., 1953; White and Sweet, 1955).

The rather massive retrograde growth of axons from the injured nerve may be related to availability of vacant Schwann cells and other non-neuronal cells that could provide the sprouts with neurotrophins or matrix molecules. A similar situation is observed during normal development of the ventral root (Nilsson Remahl et al., 2008). Vacant Schwann cells are numerous during the time period when unmyelinated axons invade the VR from its distal end. These vacant Schwann cells may provide the ingrowing axons with structural and trophic support by expression of neurotrophins and presented by the p75 receptors (Johnson et al., 1988; Zhou and Li, 2007). However, also other functions for p75 can be considered in this context. The p75 reactive Schwann cells also seem to be of importance for myelination (Song et al., 2006). Animals with a knockout for 775 have been shown to have an impaired Schwann cell migration (Yamauchi et al., 2004). In addition, p75 has been reported to mediate apoptosis in Schwann cells during development as well as after injury (Syroid et al., 2000).

In the injured sciatic nerve retrograde loss of motor axons is very limited in older animals and a similar massive growth of recurrent growth does not seem to occur later during development (Risling et al., 1983a). The axon bundles were accompanied by p75 positive cells in both the root fascicles and the pia mater, but not in the CNS. It may thus be suggested that neurotrophin presenting $\mathrm{p} 75$ positive cells could facilitate axonal growth into the pia mater and that the lack of such cells in the CNS compartment might contribute to the failure of growth into the CNS. A close relation between regrowing axons, after spinal cord lesion or ventral root replantation, and meningeal cells has been observed in previous studies (Ramón y Cajal, 1928; Risling et al., 

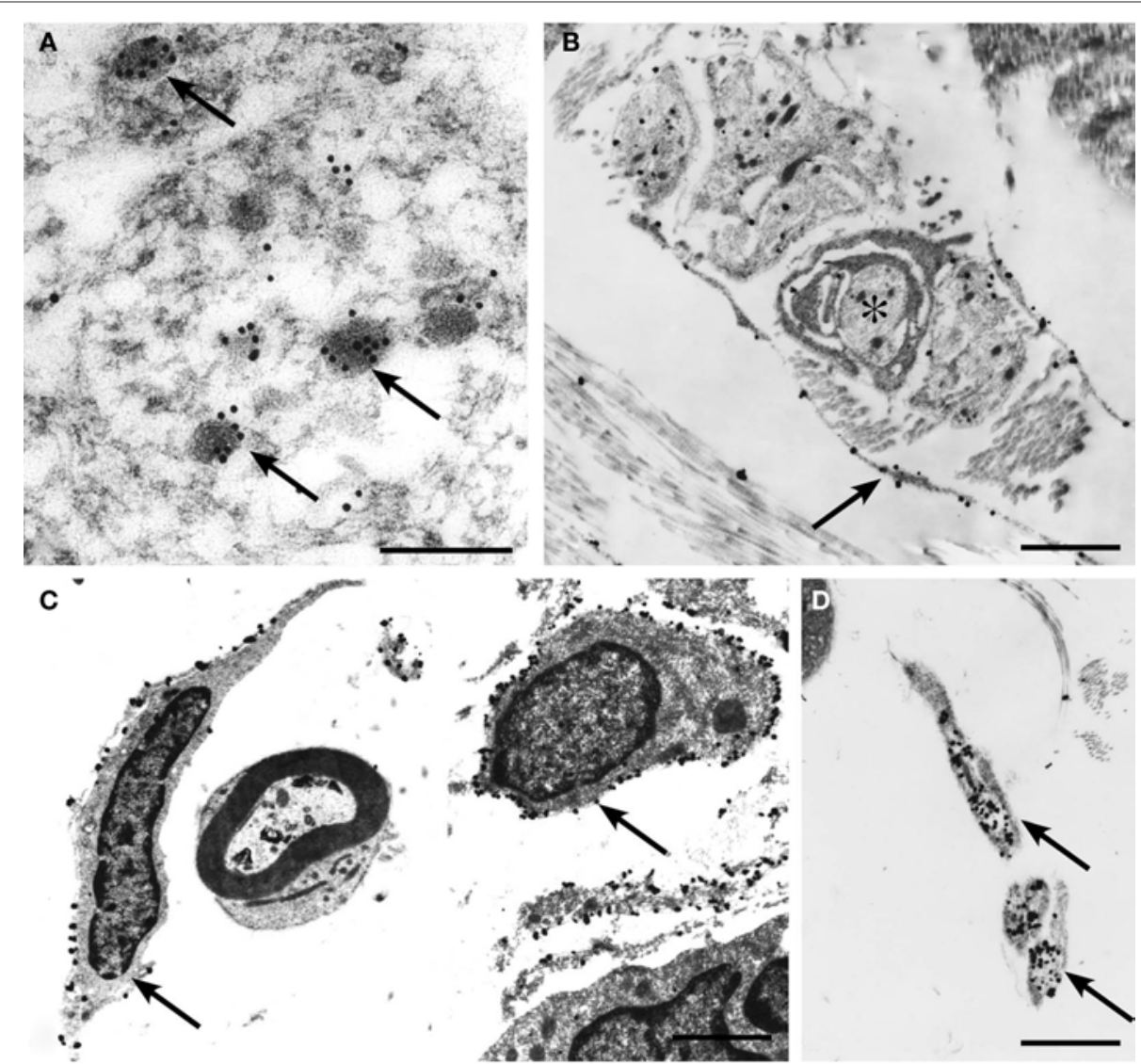

FIGURE 5 | Electron micrographs showing immunogold-labeled sections. (A) Unmyelinated axon profiles in the vicinity of the CNS-PNS border in a specimen (180-days survival) embedded in LRWhite. A number of dense cored vesicles labeled with SP antibodies and secondary antibodies conjugated with 10-nm gold particles (Scale bar $=0.25 \mu \mathrm{m}$ ). The gold particles seem to be preferentially associated to dense cored vesicles. (B,C) Electron micrographs from a specimen incubated with $\mathrm{p} 75$ antibodies. After incubation with gold-conjugated secondary antibodies and silver enhancement a strong labeling of unmyelinated axons is observed in juxtamedullary ventral root fascicles
(B). One of the axon profiles is indicated by an asterisk. A strong labeling of non-neural cell was observed in both root fascicles and the pia mater (arrows). No such labeling was observed in the spinal cord. The electron micrograph (D) shows a specimen incubated with GAP-43 antibodies. After incubation with gold-conjugated secondary antibodies and silver enhancement a strong labeling of unmyelinated axons (arrows) is present both in the juxtamedullary ventral root fascicles. A similar labeling was present in the pia mater, but not inside the spinal cord. Ninety-days survival time after sciatic nerve resection (B-D). Scale bars $\mathbf{B}-\mathbf{D}=1 \mu \mathrm{m}$.
1991, 1992a,b; Frisén et al., 1998). The possible actions of meningeal cells in axon regrowth remains to be elucidated, but meningeal cells have been shown to prevent the formation of the fibrotic scar in CNS injury (Teng et al., 2008) and thereby contribute to axon regeneration. Furthermore, data from in vitro studies suggest that meningeal cells can facilitate axonal growth and orientation (Walsh et al., 2005). However, within a dense spinal cord lesion scar it is possible that the meningal cells have a different phenotype and more restrictive role (Sandvig et al., 2004). On the other hand, in the cases of successful outgrowth of motor axons after a lesion inside the ventral funiculus the scar tissue has had a trabecular appearance with just a thin investment of CNS glia surrounding the axons in their way through a tissue composed of meningal cells, matrix molecules and vessels lacking blood-brain barrier (BBB) function (Risling et al., 1983b, 1989, 1992a, 1993).

A few examples of myelinated axons with a long unmyelinated segment at the ventral root CNS-PNS border were encountered (cf. normal development of the S1 dorsal spinal root, Nilsson Remahl et al., 1998).
Early postnatal sciatic nerve lesions seem to induce a general growth retardation in motoneurons (Cullheim et al., 1984) and a decrease in conduction velocities. Our present observations show that this injury results in remote effects at the CNS-PNS border and that this region could be crucial in terms of propagation of action potentials. The reason for this atypical ensheathment and myelination is unknown, and reminds of the appearance of the myelination of the optic nerve head (Hildebrand et al., 1985) and the dendritic myelination in the olfactory bulb (Remahl and Hildebrand, 1985). Both these areas seem to contain a number of $\mathrm{p} 75$ positive meningeal cells and it has been suggested that the BBB is less tight at these sites (Hildebrand et al., 1985). Also, in the scar tissue after ventral funiculus we have reported abnormal myelination, invasion of p75 meningeal cells and a persistent defect in the BBB (Risling et al., 1983b, 1989, 1992a). However, in the present material the general configuration of the border zone was similar to the situation in normal animals. Thus, the glial cone and glial fringe was unchanged as well as the vascular density. 

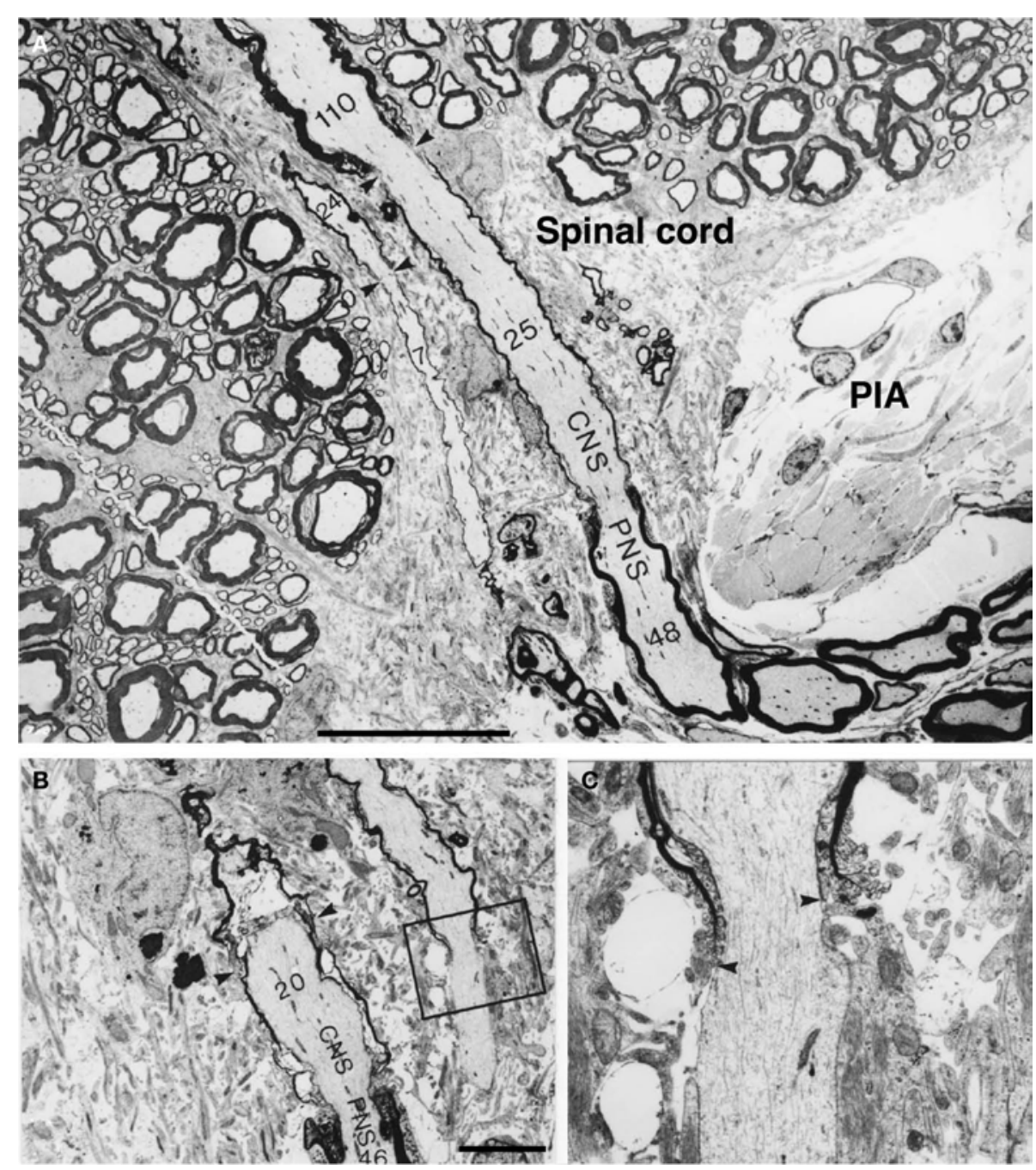

FIGURE 6 | Electron micrographs showing motor axons close to the CNS-PNS border in a transverse section, from a cat surviving for 90 days after the sciatic nerve injury. (A) Two motor axons show up longitudinally in this section as they enter the edge of the ventral root CNS compartment. Both axons are invested by unusually thin myelin sheaths in the ventral root CNS compartment. The number of myelin lamellae at different levels has been indicated in each axon. Arrowheads indicate the location of two nodes of Ranvier. One of these represents a CNS-PNS border node. Note that a complete (abnormally short) internode is covered by this micrograph. $\mathrm{PIA}=$ pia mater. Scale bar $=20 \mu \mathrm{m}$. In the micrographs (B,C), two longitudinally sectioned axons are shown in the CNS compartment. The numbers of myelin lamellae (which were counted at high magnification directly in the electron microscope) have been indicated in the axons. The CNS-PNS border node (arrowheads) of one of the axons is included in the micrograph. Note that the number of lamellae in the last CNS-type myelin sheath (20) is less than half of the number observed in the first PNS-type sheath (46). The other axon, which is thinner, presents an unmyelinated segment in the CNS compartment. (C) A high magnification picture showing the "heminode" that is indicated by the box in (B). A close examination of the site where this myelin sheath terminated (arrowheads) revealed that some of the characteristics of the nodes of Ranvier, like axolemmal undercoating, are lacking. Scale bar $=5 \mu \mathrm{m}$.
An increased knowledge of the pathology of the CNS-PNS border region may hopefully be of benefit for future studies on the treatment of lesions to nerve roots (Fraher, 1999). One important question is if the recurrent sprouts can generate spontaneous pain from the end clubs or by interaction between fibers in the network that is formed in the ventral root and the pia mater. Can they give the ventral root, the sciatic nerve or the pia mater an increased sensitivity for mechanical stimulation? Could there be any vascular effects by a tentative release of substance P or CGRP? Could substance P, which is a mitogen for fibroblasts (Nilsson et al., 1985), induce a proliferation of the pia mater over time? The present findings show that axonal sprout actually can penetrate the CNS-PNS border and remain in the ventral funiculus for a limited time without any direct lesion to the border region.

\section{ACKNOWLEDGMENTS}

This study was supported by grants from the Swedish Research Council, Karolinska Institutet, Marcus and Amalia Wallenberg, Magn. Bergwalls stiftelse, Stiftelsen Lars Hiertas minne, and Stiftelsen Claes Groschinskys Minnesfond. 


\section{REFERENCES}

Carlstedt, T. (1977). Observations on the morphology at the transition between the peripheral and the central nervous system in the cat. IV. Unmyelinated fibres in S1 dorsal rootlets. Acta Physiol. Scand. Suppl. 446, 61-72.

Carlstedt, T. (1985). Dorsal root innervation of spinal cord neurons after dorsal root implantation into the spinal cord of adult rats. Neurosci. Lett. 55, 343-348.

Carlstedt, T., Anand, P., Hallin, R., Misra, P.V., Noren, G., and Seferlis, T. (2000). Spinal nerve root repair and reimplantation of avulsed ventral roots into the spinal cord after brachial plexus injury. J. Neurosurg. 93, 237-247.

Carlstedt, T., Cullheim, S., Risling, M., and Ulfhake, B. (1988). Mammalian rootspinal cord regeneration. Prog. Brain Res. 78, 225-229.

Carlstedt, T., Cullheim, S., Risling, M., and Ulfhake, B. (1989). Nerve fibre regeneration across the PNS-CNS interface at the root-spinal cord junction. Brain Res. Bull. 22, 93-102.

Coggeshall, R.E. (1980). Law of separation of function of the spinal roots. Physiol. Rev. 60, 716-755.

Coggeshall, R. E., Coulter, J. D., and Willis, W. D. Jr. (1974). Unmyelinated axons in the ventral roots of the cat lumbosacral enlargement. J. Comp. Neurol. 153, 39-58.

Coggeshall, R. E., Emery, D. G., Ito, H., and Maynard, C.W. (1977). Unmyelinated and small myelinated axons in rat ventral roots. J. Comp. Neurol. 173.

Cranefield, P.F. (1974). The Way In and the Way Out. New York: Futura.

Cullheim, S., Carlstedt, T., Linda, H., Risling, M., and Ulfhake, B. (1989). Motoneurons reinnervate skeletal muscle after ventral root implantation into the spinal cord of the cat. Neuroscience 29, 725-733.

Cullheim, S., Risling, M., Berglund, S., and Lindå, H. (1984). Conduction velocities of nerve fibers proximal to muscle nerve transection in kittens and adult cats. Exp. Neurol. 84, 484-487.

Fraher, J. P. (1999). The transitional zone and CNS regeneration. J. Anat. 194 (Pt 2), 161-182.

Frisén, J., Risling, M., Korhonen, L., Zirrgiebel, U., Johansson, C. B., Cullheim, S., and Lindholm, D. (1998). Nerve growth factor induces process formation in meningeal cells: implications for scar formation in the injured CNS. J. Neurosci. 18, 5714-5722.

Frykholm, R., Hyde, J., Norlén, G., and Skoglund, C. R. (1953). On pain sensations produced by stimulation of ventral roots in man. Acta Physiol. Scand. 29, 455-469.

Hildebrand, C., and Aldskogius, $\mathrm{H}$. (1976). Electron-microscopic identification of Marchi-positive bodies and argyrophilic granules in the spinal cord white matter of the guinea pig. J. Comp. Neurol. 170, 191-203.

Hildebrand, C., Remahl, S., and Waxman, S. G. (1985). Axo-glial relations in the retina-optic nerve junction of the adult rat: electron-microscopic observations. J. Neurocytol. 14, 597-617.

Johnson, E. M. Jr., Taniuchi, M., and DiStefano, P.S. (1988). Expression and possible function of nerve growth factor receptors on Schwann cells. Trends Neurosci. 11, 299-304.

Nilsson, J., von Euler,A. M., and Dalsgaard, C. J. (1985). Stimulation of connective tissue cell growth by substance $P$ and substance K. Nature 315, 61-63.

Nilsson Remahl,A. I., Masterman, T., and Risling, M. (2008). Re-utilization of Schwann cells during ingrowth of ventral root afferents in perinatal kittens. J. Anat. 213, 194-201.

Nilsson Remahl, I., Berthold, C. H., and Carlstedt, T. (1998). Redistribution of Schwann cells at the developing PNSCNS borderline. An ultrastructural and autoradiographic study on the S1 dorsal root of the cat. J. Neurocytol. 27, 85-97.

Polak, J. M., and Noorden, S. V. (1986). Immunocytochemistry. Modern Methods and Applications. Bristol: Wright.

Ramón y Cajal, S. (1928). Degeneration and Regeneration of the Nervous System. Oxford: Oxford University Press.

Remahl, S., and Hildebrand, C. (1985). Myelinated non-axonal neuronal elements in the feline olfactory bulb lack sites with a nodal structural differentiation. Brain Res. 325, 1-11.

Risling, M., Aldskogius, H., Hildebrand, C., and Remahl, S. (1983a). Effects of sciatic nerve resection on L7 spinal roots and dorsal root ganglia in adult cats. Exp. Neurol. 82, 568-580.

Risling, M., Cullheim, S., and Hildebrand, C. (1983b). Reinnervation of the ventral root L7 from ventral horn neurons following intramedullary axotomy in adult cats. Brain Res. 280, 15-23.

Risling, M., Carlstedt, T., Lindå, H., and Cullheim, S. (1991). The pia mater - a conduit for regenerating axons after ventral root teplantation. Restor. Neurol. Neurosci. 3, 157-160.

Risling, M., Dalsgaard, C. J., and Cuello, A.C. (1984a). Invasion of lumbosacral ventral roots and spinal pia mater by substance P-immunoreactive axons after sciatic nerve lesion in kittens. Brain Res. 307, 351-354.

Risling, M., Dalsgaard, C. J., Cukierman, A., and Cuello, A. C. (1984b). Electron microscopic and immunohistochemical evidence that unmyelinated ventral root axons make $\mathrm{u}$-turns or enter the spinal pia mater. J. Comp. Neurol. 225, 53-63.

Risling, M., Hildebrand, C., and Cullheim, S. (1984c). Invasion of the L7 ventral root and spinal pia mater by new axons after sciatic nerve division in kittens. Exp. Neurol. 83, 84-97.

Risling,M., Dalsgaard,C.J.,Frisen, J.,Sjogren, A.M., and Fried, K. (1994).Substance P-, calcitonin gene-related peptide, growthassociated protein-43, and neurotrophin receptor-like immunoreactivity associated with unmyelinated axons in feline ventral roots and pia mater. J. Comp. Neurol. 339, 365-386.

Risling, M., Fried, K., Linda, H., Carlstedt, T., and Cullheim, S. (1993). Regrowth of motor axons following spinal cord lesions: distribution of laminin and collagen in the CNS scar tissue. Brain Res. Bull. 30, 405-414.

Risling, M., Fried, K., Lindå, H., Cullheim S., and Meier, M. (1992a). Changes in nerve growth factor receptor-like immunoreactivity in the spinal cord after ventral funiculus lesion in adult cats. J. Neurocytol. 21, 79-93.

Risling, M., Sorbye, K., and Cullheim, S. (1992b). Aberrant regeneration of motor axons into the pia mater after ventral root neuroma formation. Brain Res. 570, 27-34.

Risling, M., and Hildebrand, C. (1981). Abnormally high content of unmyelinated axon profiles in the ventral root L7 of a cat with an abdominal neoplasm. Acta Neuropathol. 54, 169-172.

Risling, M., and Hildebrand, C. (1982). Occurrence of unmyelinated axon profiles at distal, middle and proximal levels in the ventral root L7 of cats and kittens. J. Neurol. Sci. 56, 219-231.

Risling, M., Hildebrand, C., and Aldskogius, H. (1981). Postnatal increase of unmyelinated axon profiles in the feline ventral root L7. J. Comp. Neurol. 201, 343-351.

Risling, M., Hildebrand, C., and Dalsgaard, C. J. (1987). "Unmyelinated axons in spinal ventral roots and motor cranial nerves. Do these fibres have a role in somatovisceral sensation?," in Fine Afferent Nerve Fibers and Pain, eds R. F. Schmidt, H. G. Schaible, and C. VahleHinz (Weinheim: VCH), 35-44.

Risling, M., Linda, H., Cullheim, S., and Franson, P. (1989). A persistent defect in the blood-brain barrier after ventral funiculus lesion in adult cats: implications for CNS regeneration? Brain Res. 494, 13-21.

Risling, M., Remahl, S., Hildebrand, C. and Aldskogius, H. (1980). Structura changes in kittens' ventral and dorsal root L7 after early postnatal sciatic nerve transection. Exp. Neurol. 67 265-279.

Sandvig, A., Berry, M., Barrett, L. B., Butt, A., and Logan, A. (2004). Myelin-, reactive glia-, and scar-derived CNS axon growth inhibitors: expression, receptor signaling, and correlation with axon regeneration. Glia 46, 225-251.

Song, X. Y., Zhou, F. H., Zhong, J. H., Wu, L. L., and Zhou, X. F. (2006). Knockout of p75(NTR) impairs re-myelination of injured sciatic nerve in mice. $J$. Neurochem. 96, 833-842.

Syroid,D.E., Maycox,P.J.,Soilu-Hanninen, M., Petratos, S., Bucci, T., Burrola, P., Murray, S., Cheema, S., Lee, K. F., Lemke, G., and Kilpatrick, T. J. (2000). Induction of postnatal schwann cell death by the low-affinity neurotrophin receptor in vitro and after axotomy. $J$. Neurosci. 20, 5741-5747.

Teng, X., Nagata, I., Li, H. P., KimuraKuroda, J., Sango, K., Kawamura, K., Raisman, G., and Kawano, H. (2008). Regeneration of nigrostriatal dopaminergic axons after transplantation of olfactory ensheathing cells and fibroblasts prevents fibrotic scar formation at the lesion site. J. Neurosci. Res. 86, 3140-3150.

Walsh, J. F., Manwaring, M. E., and Tresco, P. A. (2005). Directional neurite outgrowth is enhanced by engineered meningeal cell-coated substrates. Tissue Eng. 11, 1085-1094.

White, J.C., and Sweet, W. H. (1955). Pain - Its Mechanisms and Neurosurgical Control. Springfield: Charles C. Thomas.

Yamauchi, J., Chan, J. R., and Shooter, E. M. (2004). Neurotrophins regulate Schwann cell migration by activating divergent signaling pathways dependent on Rho GTPases. Proc. Natl. Acad. Sci. U.S.A. 101, 8774-8779.

Zhou, X. F., and Li, H. Y. (2007). Roles of glial p75NTR in axonal regeneration. J. Neurosci. Res. 85, 1601-1605.

Conflict of Interest Statement: The authors declare that the research was conducted in the absence of any commercial or financial relationships that could be construed as a potential conflict of interest.

Received: 22 April 2010; accepted: 28 September 2010; published online: 25 October 2010.

Citation: Remahl S, Angeria M, Nilsson Remahl I, Carlstedt $T$ and Risling $M$ (2010) Observations at the CNS-PNS border of ventral roots connected to a neuroma. Front. Neur. 1:136. doi: 10.3389/ fneur.2010.00136

This article was submitted to Frontiers in Neurotrauma, a specialty of Frontiers in Neurology.

Copyright ( $\odot 2010$ Remahl, Angeria, Nilsson Remahl, Carlstedt and Risling. This is an open-access article subject to an exclusive license agreement between the authors and the Frontiers Research Foundation, which permits unrestricted use, distribution, and reproduction in any medium, provided the original authors and source are credited. 